\title{
AANPASSING VAN GROEI- EN AANWASFORMULES VAN BAGKMAN BIJ ONTBREKEN VAN GEGEVENS UIT DE EERSTE LEVENSJAREN
}

door

\section{R. Goossens}

\section{Inleiding}

O.D.C 561.

In de laatste decenia worden steeds meer onderzoekingen gedaan over de mogelijkheid, bepaalde groeiverschijnselen langs mathematische weg te karakteriseren. Disciplines als de bosgenetica en de opbrengstleer maken hiervan dankbaar gebruik, wanneer dergelijke pogingen aan zekere vereisten voldoen waardoor, met vrij hoge nauwkeurigheid, het beschouwde groeiverloop in de tijd zou kunnen geextrapoleerd worden.

Om de wetmatigheid voor de aangroei van hoogte en diameter van een boom in funktie van de tijd wiskundig te definiëren, kan een keuze worden gedaan uit een groot aantal formules, die door onderzoekers als Spath, Hossfeld, Smalian, Hugershoff, Backman, Petterson, Robertson e.a. werden voorgesteld.

Om haar vrij grote nauwkeurigheid, de speciale manier om het groeiverschijnsel te benaderen en het universele karakter, wordt vaak gewerkt met de formule van Backman waarin de grootte y van het beschouwde groeiverschijnsel in funktie van de tijd $t$, als volgt wordt uitgedrukt :

$$
\begin{array}{ll} 
& y=c_{0} \int_{-\infty}^{x} e^{-x^{2}} d x \\
\text { met } & x=c_{1} \log t+c_{2} \\
& \text { (x als organische tijd) }
\end{array}
$$

Vooral Thomasius (4) heeft in een recente studie aangetoond dat een dergelijke groeiformule zeer goede resultaten kan opleveren mits zekere voorzorgen inacht worden genomen. Hierin gecft hij een overzicht van de diverse methodes die o.a. door Stern, Schletter, Weck, Backman en Edlen zijn uitgewerkt om de 
parameters $c_{0}, c_{1}$ en $c_{2}$ te bepalen, uitgaande van een reeks groeigegevens. Na vergelijking en bespreking van voor- en nadelen van elke werkwijze, stelt Tho masi us een nieuwe methode voor waarbij de parameters uit de groeiformule, langs de aanwasformule om kunnen berekend worden. Ter illustratie van deze methode wordt bij een boomstam, aan de hand van opeenvolgende stamschijven, de periodische hoogteaanwas afgeleid en vervolgens hieruit de groeiformule voor de hoogte van betreffende boom opgesteld en de berekende resultaten aan de werkelijkheid getoetst. Hieruit blijkt de zeer hoge nauwkeurigheid van dergelijke werkwijze, vooral in het door hem behandelde geval waar groei- en aanwasgegevens vanaf de eerste levensjaren van het individu in kwestie, voorhanden zijn.

In de praktijk komt het echter vaak voor, dat enkel een beperkt aantal gegevens beschikbaar is en dat deze gegevens zelden beginnen vanaf het eerste levensjaar.

Onderstaande studie heeft dan ook tot doel aan te tonen, dat in dergelijke gevallen de methode van Thomasius tot foutieve resultaten voert en dat bijgevolg tot een andere werkwijze dicnt overgegaan.

Als cijfermateriaal voor deze vergelijkende studie werd gebruik gemaakt van de groeigegevens voor hoogte en diameter bij Populus euramericana ov Marilandica (boniteit II), uit de opbrengsttafels van Wiedemann-Schober (5), die in tabel I zijn overgenomen.

\section{Methode volgens Thomasius}

\subsection{Algemeen}

Zoals reeds vermeld stelt de auteur zich tot doel de groeiformule aan de gegevens in kwestie aan te passen, langs de aanwasformule om, die, zoals bekend, volgende vorm heeft:

$$
\log y^{\prime}=k_{0}+k_{1} \log t+k_{2} \log ^{2} t
$$

waarin $y^{\prime}$ de jaarlijkse aanwas en $t$ de tijd in jaren voorstelt.

Eens de parameters $k_{0}, k_{1}$ en $k_{2}$ berekend, kan gemakkelijk tot de groeiformule worden overgegaan, na uitwerking van volgende gelijkheden :

$$
\begin{aligned}
& c_{0}=\frac{\mathrm{e}^{\frac{4 \mathrm{k}_{0} \mathrm{k}_{2}-\left(1+\mathrm{k}_{1}\right)^{2}}{4 \mathrm{k}_{2} \log \mathrm{e}}}}{\sqrt{-\mathrm{k}_{2} \log \mathrm{e}}} \\
& \mathrm{c}_{1}=-\frac{\mathrm{k}_{2}}{2 \sqrt{-\mathrm{k}_{2} \log \mathrm{e}}} \\
& \mathrm{c}_{2}=-\frac{1+\mathrm{k}_{1}}{2 \sqrt{-\mathrm{k}_{2} \log \mathrm{e}}}
\end{aligned}
$$


Deze op het eerste zicht omslachtige rekenwijze, wordt door Thomasius als de meest nauwkeurige aangezien, vermits een rechtstreeks gebruik van de groeiformule hetschattenvan een asymptotische waarde vooropstelt, die in alle door hem behandelde methodes tot foutieve resultaten kunnen leiden.

Om nu de parameters $k_{0}, k_{1}$ en $k_{2}$ te bepalen, wordt door Thom asius onderstaande werkwijze gevolgd :

De oorspronkelijke funktie (c) wordt eenvoudigheidshalve als volgt geschreven :

$$
\mathrm{Y}^{\prime}=\mathrm{k}_{0}+\mathrm{k}_{1} \mathrm{~T}+\mathrm{k}_{2} \mathrm{~T}^{2}
$$

met $\mathrm{Y}^{\prime}=\log \mathrm{y}^{\prime}$ en $\mathrm{T}=\log \mathrm{t}$, waarop een transformatie van koördinaten is uitgevoerd met nieuwe assen $\xi$ en $\eta$ die parallel aan $T$ en $\mathrm{Y}$ versshoven zijn en waarvan de koördinaten van de nieuwe oorsprong $\overline{\mathrm{T}}$ en $\overline{\mathrm{Y}}$ worden met

$$
\overline{\mathrm{T}}=\frac{\Sigma \mathrm{T}_{\mathrm{i}}}{\mathrm{n}} \text { en } \overline{\mathrm{Y}}=\frac{\Sigma \mathrm{Y}_{\mathrm{i}}}{\mathrm{n}} \quad(1 \leqslant \mathrm{i} \leqslant \mathrm{n})
$$

Alle getallenparen (aanwas $Y_{1}$ voor het gemiddelde $T_{1}$ van de beschouwde periode) worden vervolgens in het nieuwe systeem getransformeerd waardoor

$$
\begin{aligned}
& \xi_{1}=\mathrm{T}_{1}-\overline{\mathrm{T}} \quad \eta_{1}=\mathrm{Y}_{1}-\overline{\mathrm{Y}} \\
& \xi_{2}=\mathrm{T}_{2}-\overline{\mathrm{T}} \quad \eta_{2}=\mathrm{Y}_{2}-\overline{\mathrm{Y}} \\
& \text {. . . . } \\
& \text {. } 1 . \\
& \xi_{\mathrm{n}}=\mathrm{T}_{\mathrm{n}}-\overline{\mathrm{T}} \quad \eta_{\mathrm{n}}=\mathrm{Y}_{\mathrm{n}}-\overline{\mathrm{Y}}
\end{aligned}
$$

$\mathrm{Na}$ het opstellen van de gewone voorwaarden, waarbij de som van de kwadraten der afwijkingen minimaal moet zijn, en na oplossen van het stelsel dat hieruit voortvloeit, vindt men de gewenste koëfficienten door uitwerking van onderstaande gelijkheden :

$$
\begin{aligned}
& \mathrm{k}_{2}=\frac{\Sigma \eta_{i} \xi_{i}^{2} \Sigma \xi_{i}^{2}-\Sigma \eta_{i} \xi_{i} \Sigma \xi_{i}^{3}}{\Sigma \xi_{i}^{4} \Sigma \xi_{i}^{2}-\frac{\left(\Sigma \xi_{i}^{2}\right)^{3}}{n}-\left(\Sigma \xi_{i}^{3}\right)^{2}} \\
& k_{1}=\frac{\Sigma \eta_{i} \xi_{i}-k_{2} \Sigma \xi_{1}^{3}}{\Sigma \xi_{i}^{2}}-2 k_{2} \bar{T} \\
& k_{0}=\bar{Y}-\bar{T}\left(k_{1}+k_{2} \bar{T}\right)-k_{2} \frac{\Sigma \xi_{i}^{2}}{n}
\end{aligned}
$$


Zonder echter afbreuk te willen doen aan het basisidee van de auteur, nl. de berekeningen van $c_{0}, c_{1}$ en $c_{2}$ via de parameters van de aanwasformule, leek het toch wat omslachtig deze laatste door middel van een transformatie van koördinaten en de gelijkheden (g), (h) en (i) te berekenen. Daarbij komt nog, dat men bij dergelijke transformatie met gemiddelden werkt, wat een zekere fout bij de berekeningen teweegbrengt. Om die redenen vonden we het dan ook wenselijk de methode van Thomasius in haar praktische toepassing enigszins te wijzigen.

In tegenstelling tot de hoger besproken werkwijze, wordt, voor de berekening van de parameters $k_{0}, k_{1}$ en $k_{2}$, gebruik gemaakt van de oorspronkelijke aanwaswaarden. Voor n waarnemingen ontstaan bijgevolg $n$ gelijkheden van de vorm (c). Het opnieuw opstellen van de gewone voorwaarden, waarbij de som van de kwadraten der afwijkingen tussen berekende en gevonden waarden minimaal moet zijn, geeft aanleiding tot onderstaande stelsel :

$$
\begin{aligned}
k_{2} \Sigma \log ^{4} t_{1}+k_{1} \Sigma \log ^{3} t_{1}+k_{0} \Sigma \log ^{2} t_{1} & =\Sigma \log ^{2} t_{i} \log y_{1} \\
k_{2} \Sigma \log ^{3} t_{1}+k_{1} \Sigma \log ^{2} t_{1}+k_{0} \Sigma \log t_{1} & =\Sigma \log t_{1} \log y_{t} \\
k_{2} \Sigma \log ^{2} t_{1}+k_{1} \Sigma \log t_{i}+k_{0} n \quad & =\Sigma \log y_{1} \\
(1 \leqslant i & \leqslant n)
\end{aligned}
$$

dat bvb. met behulp van de Grout-reduktie kan worden opgelost. De aldus gevonden waarden van de parameters dienen verder, zoals gebruikelijk, in de uitdrukkingen (d), (e) en (f) gesubstitueerd; zulks levert uiteindelijk de gevraagde parameters $\mathrm{c}_{0}, \mathrm{c}_{1}$ en $\mathrm{c}_{2}$.

\subsection{Resultaten}

Ter illustratie van de bruikbaarheid en nauwkeurigheid van de methode van Tho ma sius waarover hoger sprake, wordt gebruik gemaakt van de gegevens uit tabel 1. Vermits deze gegevens ontleend werden aan de opbrengsttafels van Wiedemann-Schober, zijn zowel voor hoogte $\left(y_{h}\right)$ als voor diameter $\left(y_{d}\right)$ enkel de grootheden in funktie van de tijd bekend (respektievelijk kolommen 2 en 5). Om de methode van Thom asius te kunnen toepassen, dienden ze bijgevolgd omgezet in gemiddelde aanwaswaarden. Hiertoe werden opeenvolgende verschillen gemaakt en gedeeld door vijf, de duur van de periode, Van de aldus bekomen waarden voor hoogte en diameter wordt ecnvoudigheidshalve aangenomen dat ze juist samenvallen met het midden van elk tijdsinterval. De waarnemingsparen uit de kolommen 4, 8 en 7, 8 uit tabel 1, dienen bijgevolg als basisgegevens ter berekening van de aanwasformules van de respektievelijke hoogte $\left(y_{h}^{\prime}\right)$ en diameter $\left(y_{d}^{\prime}\right)$.

$\mathrm{Na}$ achtereenvolgende oplossingen van het stelsel (j), een eerste maal met gegevens voor hoogte en cen tweede maal met gegevens 
voor de diameter, konden volgende aanwasformules opgesteld worden :

- voor de hoogte

$$
\begin{aligned}
\log \mathrm{y}_{\mathrm{h}_{\mathrm{i}}}^{\prime}= & -0,00538785426+1,15276403 \log \mathrm{t}- \\
& -0,946434045 \log ^{2} \mathrm{t}
\end{aligned}
$$

- voor de diameter

$$
\begin{aligned}
\log y^{\prime} d_{i}= & -0,758851509+1,35609125 \log \mathrm{t}- \\
& -0,527493680 \log ^{2} \mathrm{t}
\end{aligned}
$$

Tabel 2 geeft zowel voor de hoogte als voor de diameteraanwas een vergelijking tussen de gegevens uit tabel 1 en de berekende waarden met behulp van de vergelijkingen (k) en (1).

Hieruit blijkt dat voor beide groeikenmerken de aanpassing bevredigend kan genoemd worden, rekening gehouden met de niet altijd gunstige ligging van de punten (zie figuren $1 \mathrm{en} \mathrm{2).} \mathrm{Vooral}$ bij de diameteraanwas vinden we voor de leeftijden 32,$5 ; 37,5$ en $42,5 \mathrm{j}$. cen gelijke aanwas van $1,08 \mathrm{~cm} / \mathrm{j}$. en zelfs aan de lecftijd $42,5 \mathrm{j}$. een stijging tot $1,11 \mathrm{~cm} / \mathrm{j}$. Een dergelijk verloop kan onmogelijk door de aanwasformule van Backman (c) gevolgd worden.

Opeenvolgende dunningen in het populierenbestand zijn oorzaak van dit tijdelijk opdrijven of konstant blijven van de diameteraanwas, waardoor een enigszins vervalst beeld ontstaat van het klassieke groeiverloop, ingevolge de plotse en diepgaande verandering van zekere milieufaktoren. Niettemin is voor de diameter het verschil tussen gegeven $\left(y_{a}^{\prime}\right)$ en berekende $\left(y^{\prime}{ }_{a_{1}}\right)$ aanwas in meer dan de helft van de gevallen kleiner dan of gelijk aan $1 \mathrm{~mm}$. Voor de hoogteaanwas ligt dit verschil op één uitzondering na bij een waarde kleiner dan of gelijk aan $5 \mathrm{~cm}$. Rekening gehouden met de grootheidsorde van beide kenmerken en hoger vermelde abnormaliteiten, is dit resultaat zeker meer dan bevredigend te noemen.

Steeds volgens Thomasius moeten nu zowel voor de hoogte als voor de diameter de parameters uit de respektievelijke vergelijkingen (k) en (l) in de uitdrukkingen (d), (e) en (f) gesubstitueerd worden, teneinde de respektievelijke parameters van de groeiformules te kunnen berekenen.

De resultaten van die berekening zijn opgenomen in tabel 3, samen met de reeds hoger gevonden parameters uit de aanwasformules.

Om echter te kunnen nagaan of in het geval, door ons behandeld, de methode volgens Thomasius de gewenste resultaten oplevert, dienen de waarden, uit de groeiformules berekend, vergeleken te worden met de overeenkomstige gegevens uit de opbrengsttafels van Wiedemann-Schober. 
In tabel 4 zijn de resultaten van die berekeningen ondergebracht. Hierin is duidelijk te zien, dat, zowel voor de hoogte als voor de diameter, een systematische fout ontstaat, die, in het eerste geval ruim de $4 \mathrm{~m}$ overtreft, terwijl in het ander geval, meer dan de helft van de berekende waarden $7 \mathrm{~cm}$ te klein zijn.

Deze ontoelaatbare systematische fouten vinden hun oorsprong in de methode zelf, die, zoals uit tabel 4 valt op te maken, niet bruikbaar is wanneer de gegevens van de eerste levensjaren ontbreken. In het door ons behandelde geval zijn $\mathrm{nl}$. beide aanwasvergelijkingen strikt genomen alleen geldig in het gebied gelegen tussen 10 en 60 jaar. Bij de overgang van de aanwasvergelijking naar de groeivergelijking (zie hoger) wordt echter onwillekeurig gebruik gemaakt van het gebied gelegen tussen 0 en 10 jaar. Daar in geen van beide gevallen de aanwasvergelijking door gegevens uit dit gebied gekontroleerd wordt, moet dit fataal aanleiding geven tot fouten als hoger aangetoond.

\section{Grafische methode}

\subsection{Algemeen}

Dé methode door ons uitgewerkt is, in princiep, verwant met deze van Backman (1). Zij steunt op de eigenschap, dat elk groeifenomeen naar een asymptotische waarde streeft, voorgesteld door het symbool $\mathrm{J}$.

Deelt men bijgevolg elk gegeven door die grootheid, dan volgt uit de groeiformule $(a, b)$, dat, voor een ideaal groeiverloop en in een assenstelsel met absis de tijd $t$ en met ordinaat $y / J$, de aldus bekomen punten met koördinaten $(t ; y / J)$ op een rechte zullen gelegen zijn wanneer deze assen respektievelijk volgens een logaritmische en volgens cen waarschijnlijkheidsschaal zijn ingedeeld. Hierbij dient opgemerkt, dat de waarden voor $\mathrm{x}$ die hierbij nodig zijn met behulp van de tabellen van de gecummuleerde waarschijnlijkheid (Hald (2)) worden bepaald, waarin u gelijk is aan $\times \sqrt{2}$.

Gaat men nu in de praktijk de waarde van J zolang schatten tot de punten in vernoemd assenstelsel op een rechte of praktisch op een rechte liggen; dan kunnen de parameters $c_{0}$, $c_{1}$ en $c_{2}$ uit de groeiformule rechtstreeks worden bepaald door met behulp van de methode der kleinste kwadraten, aan vernoemde punten een rechte aan te passen.

Praktisch komt het hierop neer onderstaande gelijkheden uit te werken :

$$
c_{2}=\frac{\Sigma x_{1} \Sigma \log ^{2} t_{i}-\Sigma \log t_{i} \Sigma x_{i} \log t_{1}}{n \Sigma \log ^{2} t_{1}-\left(\Sigma \log t_{1}\right)^{2}}
$$




$$
c_{1}=\frac{\Sigma \mathrm{x}_{\mathrm{i}}-\mathrm{nc}_{2}}{\Sigma \log \mathrm{t}_{\mathrm{i}}}
$$

Voor de parameter $c_{0}$ geldt de eenvoudige betrekking :

$$
\mathrm{c}_{0}=\frac{\mathrm{J}}{\sqrt{\pi}}
$$

Omgekeerd kan nu ook tot de aanwasformule worden overgegaan, wanneer $\mathrm{c}_{0}, \mathrm{c}_{1}$ en $\mathrm{c}_{2}$ gekend zijn, door uitwerken van onderstaande gelijkheden :

$$
\begin{aligned}
& \mathrm{k}_{0}=\log \left(\mathrm{c}_{0} \mathrm{c}_{1} \log \mathrm{e}\right)-\mathrm{c}_{2}^{2} \log \mathrm{e} \\
& \mathrm{k}_{1}=-2 \mathrm{c}_{1} \mathrm{c}_{2} \log \mathrm{e}-1 \\
& \mathrm{k}_{2}=-\mathrm{c}_{1}^{2} \log \mathrm{e}
\end{aligned}
$$

Zoals verder zal worden aangetoond, geeft deze methode zeer goede uitslagen, waarbij de nauwkeurigheid, zowel voor de groeials voor de aanwasformules even groot blijft.

Alhoewel er reeds diverse methodes bestaan waarmee de groeiformule rechtstreeks kan worden berekend (cfr. Stern, Weck, Backman, e.a. (4)) onderscheidt zich de methode door ons voorgesteld van voorgaande werkwijzen. Zij steunt inderdaad niet op wat men heel dikwijls «zeer goed gelegen punten " noemt of in andere gevallen met punten die speciale eigenschappen vertonen in verband met de organische tijd; maar houdt inderdaad wel degelijk met alle gegevens rekening. T.o.v. de andere methode van Backman (1) waarbij eveneens met alle gegevens wordt gewerkt en met behulp van de methode der kleinste kwadraten een rechte wordt aangepast, ligt het verschil hier in het feit, dat de geschiktheid van J grafisch wordt getoetst. Enkel wanneer de punten op een rechte of nagenoeg op een rechte gelegen zijn, wordt overgegaan tot de uitwerking van (m), (p) en (q), wat veel rekenwerk spaart zonder nochtans de nauwkeurigheid te schaden, zoals verder zal worden aangetoond.

\subsection{Resultaten}

Zowel voor de gegevens voor de hoogte als voor de diameter uit tabel 1 (respektievelijk de kolommen 2 en 5), werden de overeenkomstige asymptotische waarden $J_{h 1}$ en $J_{a}$ grafisch bepaald, zoals in paragraaf 31 uiteengezet.

$\mathrm{Na}$ deling van alle waarnemingen door de geschikte asymptotische waarde, werden met de aldus bekomen relatieve grootheden $y_{1} / J$ de overeenkomstige waarden van $u_{i}$ en bijgevolg ook van 
$\mathrm{x}_{1}$ uit de tabellen van Pearson afgeleid. Aan de hand van de getallenparen $\left(t_{1} ; x_{i}\right)$ en de grootheid $J$, werden nu zowel voor hoogte als voor diameter de uitdrukkingen $(m)$, (p) en (q) uitgewerkt. Het resultaat van die berekeningen is opgenomen in tabel 6 , terwijl de grafische voorstelling van beide groeiformules in figuur 3 is afgebeeld.

Zoals bij de methode van Thomasius werden nu ook voor deze groeiformules een vergclijking gemaakt tussen berekende en gegeven grootheden uit de opbrengsttafels van WiedemannSchober. Tabel 5 geeft hiervan een overzicht.

Uit deze tabel blijkt duidelijk de goede overeenstemming van de berekende met de gegeven waarden. Voor de hoogte is praktisch in de helft van de gevallen de fout nul, terwijl in de overige gevallen meestal de $10 \mathrm{~cm}$ niet wordt overschreden. Voor de diameter ligt nagenoeg in $50 \%$ van de gevallen de fout bij $1 \mathrm{~mm}$. Rekening gehouden met de oorsprong en de grootheidsorde van de gegevens, zijn de resultaten zowel voor de hoogte als voor de diameter, meer dan bevredigend.

Alhoewel het in de praktijk minder vaak voorkomt, dat men naast de groeiformule ook nog de aanwasformule wenst te berekenen, werden deze berekeningen vervolgens toch doorgevoerd om een volledige vergelijking te kunnen maken met de methode van Thomasius. Door zowel voor hoogte als voor diameter de parameters $c_{0}, c_{1}$ en $c_{2}$ uit tabel 6 in de uitdrukkingen ( $\mathrm{r}$ ), (s) en (v) te substitueren, kunnen de parameters voor de aanwasformules aldus worden berekend. De resultaten hiervan zijn eveneens in tabel 6 opgenomen.

Tenslotte is ook voor dit geval de vergelijking van de met deze aanwasformules berekende aangroei voor hoogte en diameter en de gegevens uit tabel 1 (kolommen 4 en 7) doorgevoerd en in tabel 7 ondergebracht.

Hieruit blijkt dat deze onrechtstreekse aanwasberekeningen (nl. langs de groeiformules om) nagenoeg dezelfde nauwkeurigheid opleveren als de rechtstreekse berekeningen met de methode van Thomasius.

\section{Besluiten}

Om in het geval van Populus euramericana cv Marilandica, de methode van Tho masius met onze werkwijze statistisch te kunnen vergelijken, werden zowel voor hoogte als voor diameter, de gemiddelde afwijkingen bepaald tussen de berekende en de gegeven aanwas en groei; respektievelijk voorgesteld door de symbolen $\overline{\Delta y}^{\prime}$ en $\overline{\Delta y}$. De hierbij horende spreidingen zijn respektievelijk met $\mathrm{S} \overline{\Delta y^{\prime}}$ en $\mathrm{S} \Delta \mathrm{y}$ aangeduid. In tabel 7 is hiervan een overzicht gegeven. 
Hieruit blijkt, dat, voor de aanwasformules, de verschillen tussen de gegeven en de berekende waarden gemiddeld nagenoeg nul zijn. Statistisch $(P=0,01)$ is bij de aanwasformules geen verschil in nauwkeurigheid aan te tonen tussen de methode van Thomasius en de door ons vitgewerkte grafische methode. Voor de groeiformules is zulks bij eenzelfde P-waarde wel mogelijk, gezien bij gebruik van de methode van Thomasius zowel voor de hoogte als voor de diameter vrij aanzienlijke fouten ontstaan, die in het gemiddelde respektievelijk $4,6 \mathrm{~m}$ en $7,9 \mathrm{~cm}$ bedragen.

Het is dus uit wat vooraf gaat duidelijk gebleken, dat de grafische methode de te volgen weg is in de gevallen waar groeigegevens uit de eerste levensjaren ontbreken. Hierbij is eveneens aangetoond, dat de nauwkeurigheid van dergelijke methode zeer groot is, en waarschijnlijk gelijkwaardig aan de methode van Thom asius wanneer toegepast in het geval van een volledige serie waarnemingen. Het is trouwens niet uitgesloten de grafische methode ook in laatst genoemd geval met evenveel succes aan te wenden.

Alhoewel het wellicht duidelijk is geworden, dat de methode van Thomasius onbruikbaar is in die gevallen waar de groeigegevens van de eerste jaren ontbreken, blijft zij nochtans meest aangewezen voor alle andere gevallen waar dergelijke gegevens over de jeugdgroei wel voorhanden zijn. Inderdaad, deze Thomasius methode maakt enkel gebruik van wiskundig verantwoorde berekeningen, die zowel voor de parameters van de groei- als van de aanwasformule beroep doet op exakte en beproefde formules, die voor automatische verwerkingen met electrische rekenmachines of computers, geen grote moeilijkheden opleveren en de onderzoekers op geen enkel ogenblik voor een keuze stellen.

Praktisch zouden we bijgevolg beide methodes in hun specifiek geval willen toegepast zien, vermits de grafische methode dan toch voor serie-berekeningen het nadeel bezit de asymptotische waarde enkele malen te moeten toetsen om uiteindelijk een beslissende keuze te kunnen maken. Wanneer men echter over een computer beschikt zou dit laatste nadeel voor een groot deel kunnen worden opgeheven. Inderdaad, de programmatie van het probleem zou derwijze dienen uitgewerkt dat voor opeenvolgende asymptotische waarden (met interval $\Delta \mathrm{J}$ ) de aanpassing volgens de uitdrukking en (m), (p) en (q) wordt doorgevoerd. Door nu steeds na elke aanpassing de fout te berekenen die een dergelijke aanpassing met zich brengt en deze te toetsen aan een vooropgestelde nauwkeurigheidsgrens, kan alzo de keuze van J automatisch door de computer gebeuren wanneer vooropgestelde grens wordt bereikt. In dergelijk geval is de zgn. "grafische methode " (die in feite dan geen gebruik meer maakt van de grafische voorstelling) zowel voor een volledige als voor een onvolledige serie waarnemingen zonder praktische bezwaren aan te wenden. 
TABEL 1

Gegevens voor hoogte- en diametergroei van Populis euramericana cv. Marilandica (II ${ }^{\circ}$ boniteit naar Wiedemann-Schober)

\begin{tabular}{|c|c|c|c|c|c|c|c|}
\hline \multirow[b]{2}{*}{$\begin{array}{l}\text { leeftijd } \\
\text { in jaren } \\
(\mathrm{t})\end{array}$} & \multicolumn{3}{|c|}{ Hoogte } & \multicolumn{3}{|c|}{ Diameter } & \multirow[b]{2}{*}{$\begin{array}{l}\text { leeftijd } \\
\text { in jaren } \\
(t)\end{array}$} \\
\hline & $\begin{array}{c}\text { hoogte } y_{h} \\
\text { in m } \\
\text { (2) }\end{array}$ & $\begin{array}{c}\text { perio- } \\
\text { dische } \\
\text { aanwas } \\
\text { in } \mathrm{m} \\
\text { (3) }\end{array}$ & $\begin{array}{c}\text { gemid- } \\
\text { delde } \\
\text { aanwas } \\
\text { in } \mathrm{m} \\
\mathrm{y}^{\prime} \mathrm{h} \\
(4)\end{array}$ & $\begin{array}{c}\text { diameter } \\
y_{a} \text { in } \mathrm{cm} \\
\text { (5) }\end{array}$ & $\begin{array}{l}\text { perio- } \\
\text { dische } \\
\text { aanwas } \\
\text { in } \mathrm{cm} \\
\text { (6) }\end{array}$ & $\begin{array}{l}\text { gemid- } \\
\text { delde } \\
\text { aanwas } \\
\text { in } \mathrm{cm} \\
\mathrm{y}_{\mathrm{d}}^{\prime} \\
(7)\end{array}$ & \\
\hline 10 & 13.5 & \multirow{2}{*}{6.4} & \multirow{2}{*}{1.28} & 16.2 & \multirow{2}{*}{5.5} & \multirow{2}{*}{1.10} & \multirow[b]{2}{*}{12.5} \\
\hline 15 & 19.9 & & & 21.7 & & & \\
\hline 20 & 23.9 & 4.0 & 0.80 & 29.6 & 7.9 & 1.58 & 17.5 \\
\hline 25 & 27.1 & 3.2 & 0.64 & 36.6 & 7.0 & 1.40 & 22.5 \\
\hline 30 & 29.7 & 2.6 & 0.52 & 42.7 & 6.1 & 1.22 & 27.5 \\
\hline 35 & 31.8 & 2.1 & 0.42 & 48.1 & 5,4 & 1,08 & 32.5 \\
\hline 40 & 33.4 & 1.6 & 0.32 & 53.5 & 5.4 & 1.08 & 37.5 \\
\hline 45 & 34.7 & 1.3 & 0.26 & 58.9 & 5.4 & 1.08 & 42.5 \\
\hline 50 & 35.7 & 1.0 & 0.20 & 64.4 & 5.5 & 1.10 & 47.5 \\
\hline 55 & 36.4 & 0.7 & 0.14 & 69.7 & 5.3 & 1.06 & 52.5 \\
\hline 60 & 36.9 & 0.5 & 0.10 & & 5.2 & I.04 & 57.5 \\
\hline
\end{tabular}

TABEL 2

Vergelijking tussen de gegeven aanwas en de berekende volgens de methode van Thom asius

\begin{tabular}{|c|c|c|c|c|c|c|}
\hline \multirow[b]{2}{*}{$\begin{array}{l}\text { leeftijd } \\
\text { in jarcen } \\
(\mathrm{t})\end{array}$} & \multicolumn{3}{|c|}{ Hoogte } & \multicolumn{3}{|c|}{ Diameter } \\
\hline & $\begin{array}{c}\text { gemiddelde } \\
\text { aanwas } \\
\text { in } \mathrm{m} \\
\mathrm{y}_{\mathrm{h}}^{\prime} \\
(2)\end{array}$ & $\begin{array}{l}\text { berekende } \\
\text { aanwas } \\
\text { in } \mathrm{m} \\
\mathrm{y}^{\prime} \mathrm{h}(\mathrm{i}) \\
(3)\end{array}$ & $\begin{array}{c}\begin{array}{c}\text { fout in } \mathrm{m} \\
\Delta=\mathrm{y}^{\prime} h(i)-\mathrm{y}^{\prime} \mathrm{h}\end{array} \\
\text { (4) }\end{array}$ & $\begin{array}{c}\text { gemiddelde } \\
\text { aanwas } \\
\text { in } \mathrm{cm} \\
\mathrm{y}^{\prime} \mathrm{d} \\
\text { (5) }\end{array}$ & $\begin{array}{l}\text { berekende } \\
\text { aanwas } \\
\text { in } \mathrm{cm} \\
\mathrm{y}^{\prime} \mathrm{d}(1) \\
(6)\end{array}$ & $\begin{array}{c}\text { fout in } \mathrm{cm} \\
\Delta=\mathrm{y}^{\prime} \mathrm{d}(\mathrm{i})-\mathrm{y}^{\prime} \mathrm{d} \\
\text { (7) }\end{array}$ \\
\hline $\begin{array}{l}12.5 \\
17.5 \\
22.5 \\
27.5 \\
32.5 \\
37.5 \\
42.5 \\
47.5 \\
52.5 \\
57.5\end{array}$ & $\begin{array}{l}1.28 \\
0.80 \\
0.64 \\
0.52 \\
0.42 \\
0.32 \\
0.26 \\
0.20 \\
0.14 \\
0.10\end{array}$ & $\begin{array}{l}1.33 \\
0.92 \\
0.66 \\
0.49 \\
0.38 \\
0.29 \\
0.23 \\
0.19 \\
0.15 \\
0.12\end{array}$ & $\begin{array}{r}+0.05 \\
+0.12 \\
+0.02 \\
-0.03 \\
-0.05 \\
-0.03 \\
-0.03 \\
-0.01 \\
+0.01 \\
+0.02\end{array}$ & $\begin{array}{l}1.10 \\
1.58 \\
1.40 \\
1.22 \\
1.08 \\
1.08 \\
1.08 \\
1.11 \\
1.06 \\
1.04\end{array}$ & $\begin{array}{l}1.24 \\
1.29 \\
1.29 \\
1.26 \\
1.22 \\
1.17 \\
1.12 \\
1.08 \\
1.03 \\
0.99\end{array}$ & $\begin{array}{r}+0.14 \\
-0.29 \\
-0.11 \\
+0.04 \\
+0.14 \\
+0.09 \\
+0.04 \\
-0.03 \\
-0.03 \\
-0.05\end{array}$ \\
\hline
\end{tabular}


TABEL 3

Samenvattende tabel met de parameters voor groei- en aanwasformule van Backman, berekend volgens de methode van Thomasius

\begin{tabular}{|c||c|c|}
\hline parameters & hoogte & diameter \\
\hline $\mathrm{k}_{0}$ & $-0,00538785426$ & $-0,758851509$ \\
$\mathrm{k}_{1}$ & 1,15276403 & 1,35609125 \\
$\mathrm{k}_{2}$ & $-0,946434045$ & $-0,527493680$ \\
\hline $\mathrm{c}_{0}$ & 25,7704957 & 155,645035 \\
$\mathrm{c}_{1}$ & 1,47622651 & 1,10208848 \\
$\mathrm{c}_{2}$ & $-1,67891337$ & $-2,46128166$ \\
\hline
\end{tabular}

TABEL 4

Vergelijking tussen de gegeven hoogten en diameters en de berekende volgens de methode van Thomasius

\begin{tabular}{|c|c|c|c|c|c|c|}
\hline \multirow[b]{2}{*}{$\begin{array}{c}\text { leeftijd } \\
\text { in jaren } \\
(\mathrm{t})\end{array}$} & \multicolumn{3}{|c|}{ Hoogte } & \multicolumn{3}{|c|}{ Diameter } \\
\hline & $\begin{array}{c}\text { gegeven } \\
\text { hoogte } \\
\text { in m } \\
y_{h} \\
(2) \\
\end{array}$ & $\begin{array}{c}\text { berekende } \\
\text { hoogte } \\
\text { in m } \\
y_{h(1)} \\
(3) \\
\end{array}$ & $\begin{array}{c}\text { fout in } m \\
\Delta=y_{h(1)}-y_{h} \\
\text { (4) }\end{array}$ & $\begin{array}{c}\text { gegeven } \\
\text { diameter } \\
\text { in cm } \\
y_{d} \\
(5) \\
\end{array}$ & $\begin{array}{c}\text { berekende } \\
\text { diameter } \\
\text { in } \mathrm{cm} \\
y_{\mathrm{d}(\mathrm{i})} \\
(6)\end{array}$ & $\begin{array}{l}\text { fout in } \mathrm{cm} \\
\Delta=y_{d(i)}-y_{d} \\
(7)\end{array}$ \\
\hline $\begin{array}{l}10 \\
15 \\
20 \\
25 \\
30 \\
35 \\
40 \\
45 \\
50 \\
55 \\
60\end{array}$ & $\begin{array}{l}13.5 \\
19.9 \\
23.9 \\
27.1 \\
29.7 \\
31.8 \\
33.4 \\
34.7 \\
35.7 \\
36.4 \\
36.9\end{array}$ & $\begin{array}{l}17.6 \\
24.2 \\
28.8 \\
32.1 \\
34.7 \\
36.5 \\
38.0 \\
39.2 \\
40.1 \\
40.9 \\
41.5\end{array}$ & $\begin{array}{l}+4.1 \\
+4.3 \\
+4.9 \\
+5.0 \\
+5.0 \\
+4.7 \\
+4.6 \\
+4.5 \\
+4.4 \\
+4.5 \\
+4.6\end{array}$ & $\begin{array}{l}16.2 \\
21.7 \\
29.6 \\
36.6 \\
42.7 \\
48.1 \\
53.5 \\
58.9 \\
64.4 \\
69.7 \\
74.9\end{array}$ & $\begin{array}{r}8.0 \\
14.3 \\
21.3 \\
27.5 \\
33.9 \\
40.2 \\
46.6 \\
51.5 \\
57.3 \\
62.1 \\
67.0\end{array}$ & $\begin{array}{r}-8.2 \\
-7.4 \\
-8.3 \\
-9.1 \\
-8.8 \\
-7.9 \\
-6.9 \\
-7.4 \\
-7.1 \\
-7.6 \\
-7.9\end{array}$ \\
\hline
\end{tabular}


TABEL 5

Vergelijking tussen de gegevens over hoogte en diameter en de berekende volgens de grafische methode

\begin{tabular}{|c|c|c|c|c|c|c|}
\hline \multirow{2}{*}{$\begin{array}{l}\text { leeftijd } \\
\text { in jaren } \\
(t)\end{array}$} & \multicolumn{3}{|c|}{ Hoogte } & \multicolumn{3}{|c|}{ Diameter } \\
\hline & $\begin{array}{c}\text { gegeven } \\
\text { hoogte } \\
\text { in } \mathrm{m} \\
y_{\mathrm{h}} \\
(2)\end{array}$ & $\begin{array}{c}\text { berekende } \\
\text { hoogte } \\
\text { in m } \\
y_{h(1)} \\
(3) \\
\end{array}$ & $\begin{array}{c}\text { fout in } \mathrm{m} \\
\Delta=\mathrm{y}_{\mathrm{h}(\mathrm{i})}-\mathrm{y}_{\mathrm{h}} \\
\text { (4) }\end{array}$ & $\begin{array}{c}\text { gegeven } \\
\text { diameter } \\
\text { in } \mathrm{cm} \\
y_{\mathrm{d}} \\
(5) \\
\end{array}$ & $\begin{array}{c}\text { berekende } \\
\text { diameter } \\
\text { in } \mathrm{cm} \\
y_{\mathrm{d}(i)} \\
(6)\end{array}$ & $\begin{array}{c}\text { fout in } \mathrm{cm} \\
\Delta=y_{\mathrm{d}(1)}-\mathrm{y}_{\mathrm{d}} \\
\text { (7) }\end{array}$ \\
\hline $\begin{array}{l}10 \\
15 \\
20 \\
25 \\
30 \\
35 \\
40 \\
45 \\
50 \\
55 \\
60\end{array}$ & $\begin{array}{l}13.5 \\
19.9 \\
23.9 \\
27.1 \\
29.7 \\
31.8 \\
33.4 \\
34.7 \\
35.7 \\
36.4 \\
36.9\end{array}$ & $\begin{array}{l}13.2 \\
19.5 \\
23.9 \\
27.2 \\
29.8 \\
31.8 \\
33.4 \\
34.7 \\
35.6 \\
36.4 \\
37.0\end{array}$ & $\begin{array}{r}-0.2 \\
-0.4 \\
0.0 \\
+0.1 \\
+0.1 \\
0.0 \\
0.0 \\
0.0 \\
-0.1 \\
0.0 \\
+0.1\end{array}$ & $\begin{array}{l}16.2 \\
21.7 \\
29.6 \\
36.6 \\
42.7 \\
48.1 \\
53.5 \\
58.9 \\
64.4 \\
69.7 \\
74.9\end{array}$ & $\begin{array}{l}15.8 \\
21.6 \\
30.0 \\
36.0 \\
43.0 \\
48.0 \\
53.4 \\
59.0 \\
64.0 \\
70.0 \\
75.0\end{array}$ & $\begin{array}{l}-0.4 \\
-0.1 \\
+0.4 \\
-0.6 \\
+0.3 \\
-0.1 \\
-0.1 \\
+0.1 \\
+0.4 \\
+0.3 \\
+0.1\end{array}$ \\
\hline
\end{tabular}

TABEL 6

Samenvattende tabel met de parameters voor groei en aanwasformule van Backma n, berekend volgens de grafische methode

\begin{tabular}{|c||c|c|}
\hline parameters & hoogte & diameter \\
\hline $\mathrm{c}_{0}$ & 23,4138850 & 1128,38161 \\
$\mathrm{c}_{1}$ & 1,56264911 & 0,576039415 \\
$\mathrm{c}_{2}$ & $-1,90682912$ & $-2,28639677$ \\
\hline $\mathrm{k}_{0}$ & $-0,377978160$ & 0,180369756 \\
$\mathrm{k}_{1}$ & $-1,58813884$ & 0,143979189 \\
$\mathrm{k}_{2}$ & $-1,06049168$ & $-0,144108212$ \\
\hline
\end{tabular}


TABEL 7

Vergelijking tussen de gegeven aanwas en de berekende volgens de grafische methode

\begin{tabular}{|c|c|c|c|c|c|c|}
\hline \multirow[b]{2}{*}{$\begin{array}{c}\text { leeftijd } \\
\text { in jaren } \\
(t)\end{array}$} & \multicolumn{3}{|c|}{ Hoogte } & \multicolumn{3}{|c|}{ Diameter } \\
\hline & $\begin{array}{c}\text { gemiddelde } \\
\text { aanwas } \\
\text { in } \mathrm{m} \\
y^{\prime} \mathrm{h}\end{array}$ & $\begin{array}{c}\text { berekende } \\
\text { aanwas } \\
\text { in } \mathrm{m} \\
\mathrm{y}^{\prime} \mathrm{h}(\mathrm{i})\end{array}$ & $\begin{array}{c}\text { fout in } m \\
\Delta=y^{\prime} h(i)-y^{\prime}{ }_{b}\end{array}$ & $\begin{array}{c}\text { gemiddelde } \\
\text { aanwas } \\
\text { in } \mathrm{cm} \\
\mathrm{y}^{\prime} \mathrm{d}\end{array}$ & $\begin{array}{c}\text { berekende } \\
\text { aanwas } \\
\text { in } \mathrm{cm} \\
\mathrm{y}^{\prime} \mathrm{d}(\mathrm{i})\end{array}$ & $\begin{array}{l}\text { fout in } \mathrm{cm} \\
\Delta=y_{d(1)}^{\prime}-y^{\prime} d\end{array}$ \\
\hline (1) & (2) & (3) & (4) & (5) & (6) & (7) \\
\hline 12.5 & 1.28 & 1.23 & -0.05 & 1.10 & 1.46 & +0.36 \\
\hline 17.5 & 0.80 & 0.91 & $\begin{array}{r}+0.11 \\
+0.11\end{array}$ & $\begin{array}{l}1.10 \\
1.58\end{array}$ & $\begin{array}{l}1.70 \\
1.37\end{array}$ & +0.00 \\
\hline 22.5 & 0.64 & 0.68 & +0.04 & 1.40 & 1.29 & -0.21 \\
\hline 27.5 & 0.52 & 0.51 & -0.01 & 1.22 & 1.23 & $\begin{array}{r}0.01 \\
+\end{array}$ \\
\hline 32.5 & 0.42 & 0.40 & -0.02 & 1.08 & 1.17 & $\begin{array}{l}T \\
+\end{array}$ \\
\hline 37.5 & 0.32 & 0.31 & -0.01 & 1.08 & 1.12 & $\begin{array}{r}0.04 \\
+0.0 .0\end{array}$ \\
\hline 42.5 & 0.26 & 0.25 & -0.01 & 1.08 & $\begin{array}{l}1.08 \\
\text {. }\end{array}$ & 0.00 \\
\hline 47.5 & 0.20 & 0.20 & 0.00 & 1.11 & 1.04 & -0.07 \\
\hline 52.5 & 0.14 & 0.16 & $\begin{array}{r}0.02 \\
+0.0\end{array}$ & 1.06 & 1.00 & -0.06 \\
\hline 57.5 & 0.10 & 0.13 & +0.03 & 1.04 & 0.97 & -0.07 \\
\hline
\end{tabular}

\section{TABEL 8}

Vergelijking van de gemiddelde afwijking tussen de berekende en de gegeven waarden en hun spreiding

\begin{tabular}{|c|c|c|c|c|c|}
\hline \multirow{2}{*}{ symbolen } & \multicolumn{2}{|c|}{ aanwasformule } & \multicolumn{2}{|c|}{ groeiformule } & \multirow{2}{*}{ symbolen } \\
\hline & $\begin{array}{l}\text { methode van } \\
\text { Thomasius }\end{array}$ & $\begin{array}{l}\text { grafische } \\
\text { methode }\end{array}$ & $\begin{array}{l}\text { methode van } \\
\text { Thomasius }\end{array}$ & $\begin{array}{l}\text { grafische } \\
\text { methode }\end{array}$ & \\
\hline${\overline{\Delta y^{\prime}}}_{h}$ & 0.007 & 0.001 & 4.600 & -0.036 & $\overline{\Delta y_{h}}$ \\
\hline $\mathrm{S}{\overline{\Delta y^{\prime}}}_{h}$ & 0.050 & 0.045 & 0.286 & 0.150 & $\mathrm{~S} \overline{\Delta y}_{\mathrm{h}}$ \\
\hline${\overline{\Delta y^{\prime}}}_{d}$ & -0.006 & -0.002 & -7.872 & -0.050 & $\overline{\Delta y_{d}}$ \\
\hline $\mathrm{S} \overline{\Delta y}_{\mathbf{i}}^{\prime}$ & 0.129 & 0.152 & 0.687 & 0.102 & $\mathrm{~S}{\overline{\Delta y_{d}}}_{\mathrm{d}}$ \\
\hline
\end{tabular}




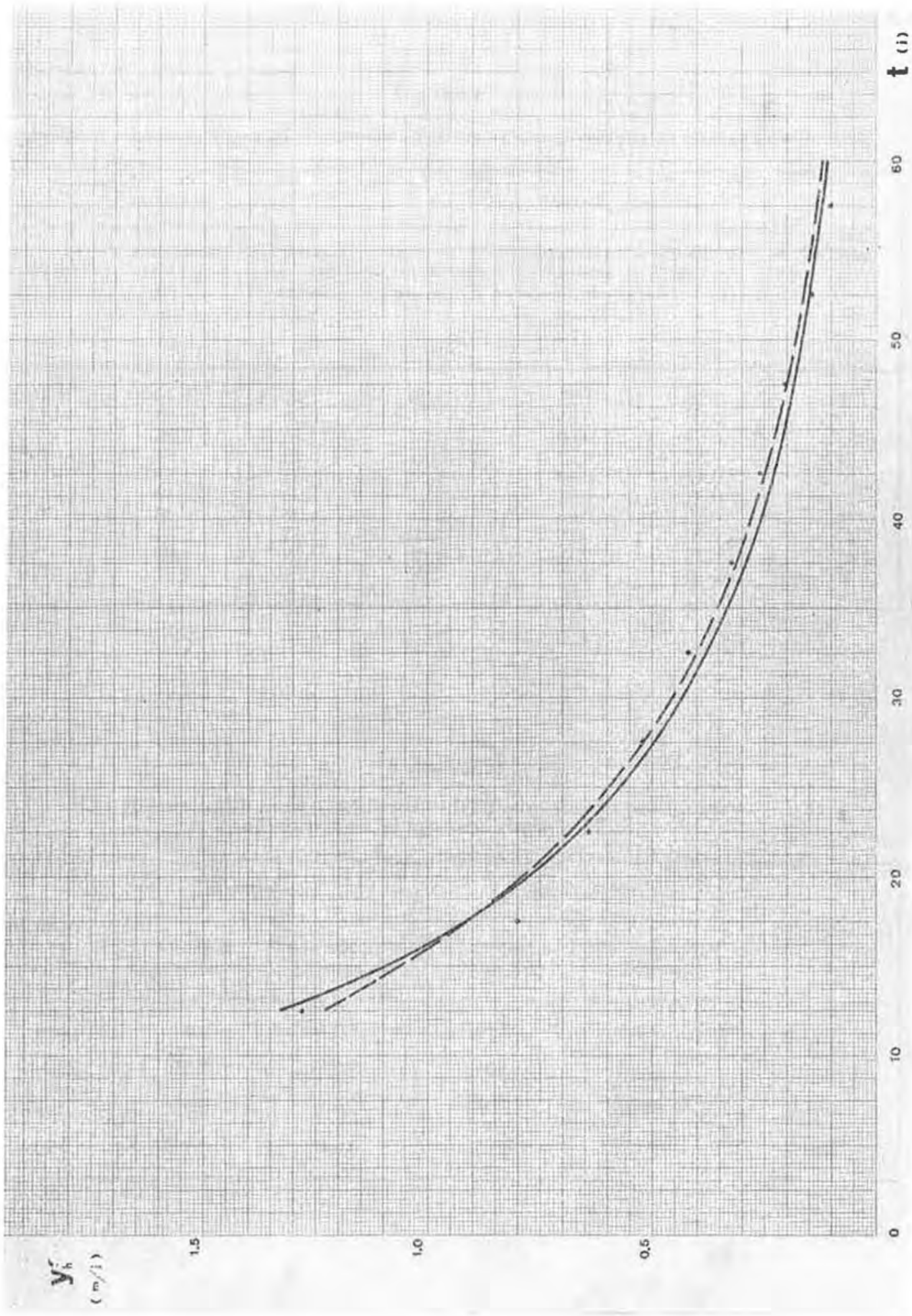

Fig. 1. Verloop van de hoogteaanwas $\left(y^{\prime} h\right)$ in funktie van de tijd $(t)$ bij Populus etramericana cv Marilandica (II ${ }^{0}$ boniteit).

.... gegevens naar Wied emann-Schober

- aanpassing volgens de methode van Thomasius

- - - aanpassing volgens de grafische methode 


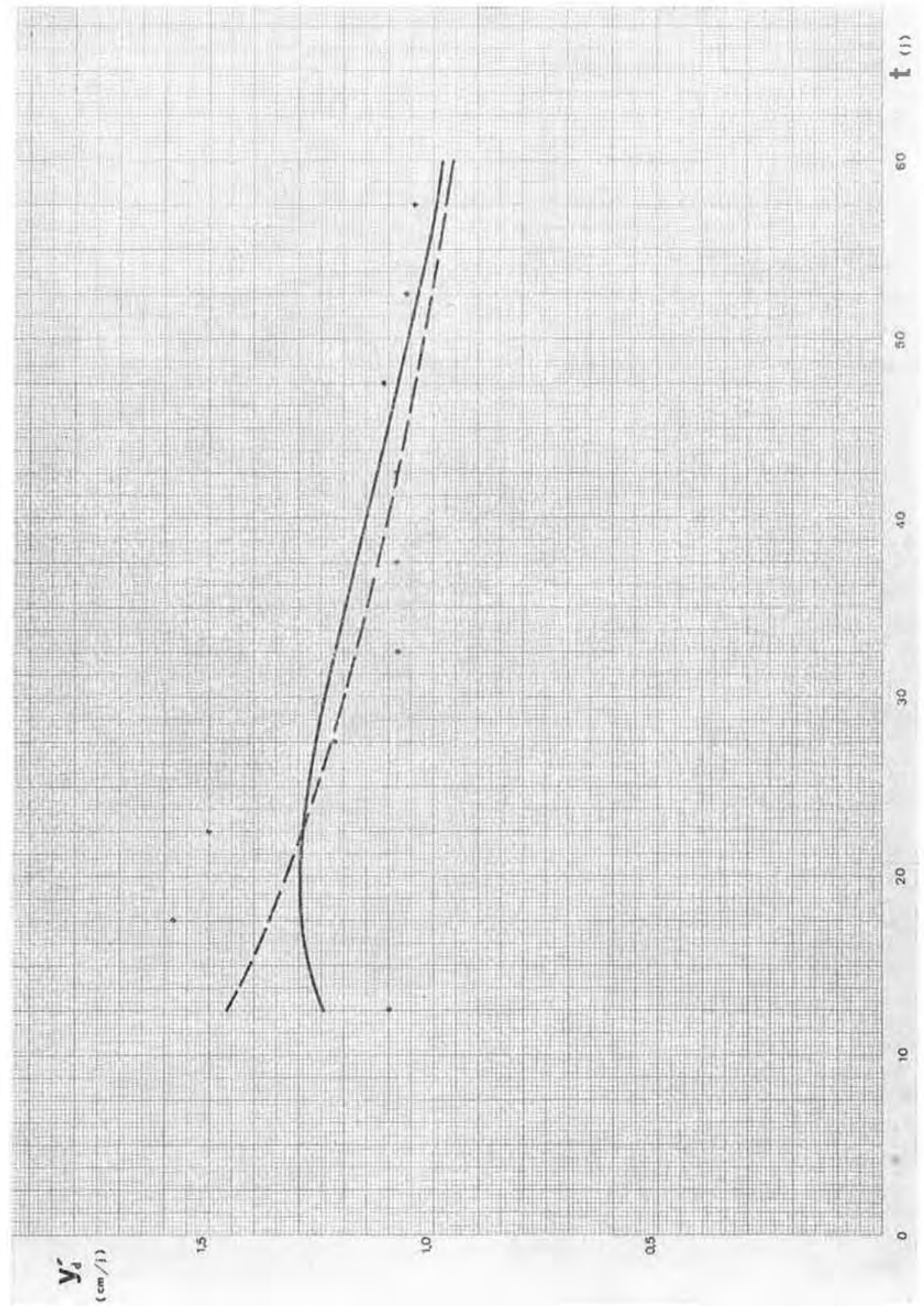

Fig. 2. Verloop van de diameteraanwas $\left(y_{a}^{\prime}\right)$ in funktie van de tijd $(t)$ bij Populus euramericana $\mathrm{cv}$. Marilandica ( $\mathrm{II}^{0}$ boniteit).

.... gegevens naar Wiedemann-Schober

aanpassing volgens de methode van Thomasius

- - aanpassing volgens de grafische methode 


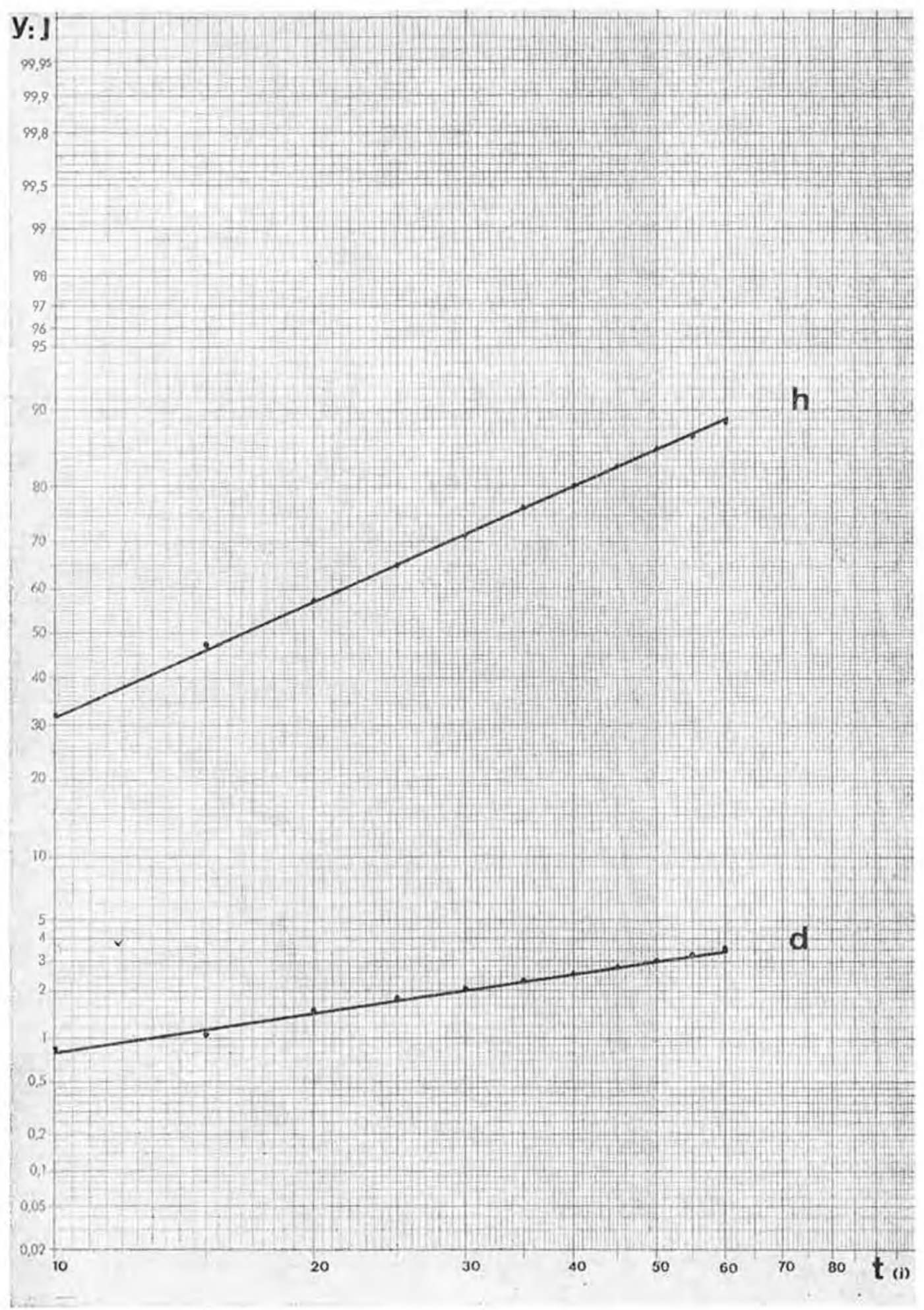

Fig. 3. Aanpassing van de rechte voor de relatie tussen de tijd (t) en de relatieve groeiwaarden (y/J) bij hoogte (h) en diameter (d) van Populus euramericana cv Marisandica (II ${ }^{0}$ boniteit naar Wied emann-Schober) 


\section{LITERATUUR}

1. BACKMAN, G. - Wachstum und organische Zeit. Bios Bd $15-1945$.

2. HALD, A. - Statistical tables and formulas. John Wiley and Sons, Inc. New York 1951,

3. LINDER, A. - Statistische Methoden. Verlag Birkhaüser - Basel 1951.

4. THOMASIUS, H. - Diskussion der Backmanschen Wachstums- und Zuwachsfunktion und der Methoden zur Bestimmung ihrer Konstanten. Archiv für Forstwesen Bd 11 (9) - 1962.

5. WIEDEMANN, E. en SGHOBER, R. - Ertragstafeln. Verlag M.u.H. Schaper - Hannover 1957.

\section{SAMENVATTING}

In bovenstaande artikel wordt cen korte uiteenzetting gegeven over de methode van Thomasius, die de parameters uit de groeiformule van Backman (a, b) langs de aanwasformule (c) om bepaalt, door uitwerking van de gelijkheden (g), (h) en (i). Eens de parameters $\mathrm{k}_{0}, \mathrm{k}_{1}$ en $\mathrm{k}_{2}$ bekend, worden ze in de gelijkheden (d), (e) en (f) gesubstitueerd, waaruit de parameters voor de grociformule kunnen teruggevonden worden.

Deze methode werd getoetst aan gegevens voor hoogte $\left(y_{h}\right)$ en diameter ( $\left.\mathrm{y}_{\mathrm{d}}\right)$ van Populus euramericana co Marilandica ( $\mathrm{II}^{\circ}$ boniteit); ontleend aan de opbrengsttafels van Wiedemann-Schober en opgenomen in tabel 1, samen met de daaruit afgeleide hoogte- $\left(y^{\prime} h\right)$ en diameteraanwas $\left(y_{d}^{\prime} d\right)$. Het resultaat van die berekeningen is samengevat in tabel 3, terwijl in de tabellen 2 en 4 zowel hoogte als voor diameter de vergelijking is gemaakt tussen de aldus berekende aanwas en groei en de gegevens uit de opbrengsttafels van Wiedemann-Schöber. Hieruit blijkt de zeer goede overeenkomst voor wat de aanwasformules en een uiterst onbevredigend resultaat voor wat de groeiformules betreft. Deze ontoelaatbare systematische fouten die voortvloeien uit de onrechtstreekse bepaling van de groeiformules, vinden hun oorsprong in de methode zelf die onbruikbaar is wanneer gegevens van de eerste levensjaren ontbreken.

Om aan dit euvel te verhelpen werd de $\mathrm{zgn}$. " grafische methode " ontwikkeld die enigszins verwant is met de methode van Backman, maar die bij het toetsen van de asymptotische waarde J, heel wat minder rekenwerk vergt. Het principe van deze methode stcunt op het feit dat bij een ideaal groeiverloop en in een assenstelsel met absis de tijd t en met ordinaat $\mathrm{y} / \mathrm{J}$, de aldus bekomen punten met koördinaten $(t ; y / J)$ op een rechte zullen gelegen zijn wanneer de assen respektievelijk volgens een logaritmische en volgens een waarschijnlijkheidsschaal zijn ingedeeld.

Praktisch komt het hierop neer de waarde van J zolang te schatten tot nagenoeg alle punten op een rechte liggen. Door aanpassing van een rechte door vernoemde punten met behulp van de uitdrukkingen $(\mathrm{m})$ en (p) kunnen $c_{2}$ en $c_{1}$ worden bepaald, terwijl $(q)$ de waarde voor $c_{0}$ oplevert.

Omgekeerd kunnen uit de kennis van de parameters van de groeiformule, de parameters van de aanwasformule worden bepaald door uitwerking van $(r)$, (s) en (v). De grafische methode werd eveneens met de gegevens uit tabel 1 beprocfd en de resultaten van de berekeningen opgenomen in tabel 6 . Zoals bij de methode van Thomasius werd vervolgens een vergelijking gemaakt tussen de berekeningen en de gegevens. De resultaten hiervan zijn voor de groei- en aanwasformules respektíeyelijk in de tabellen 5 en 7 ondergebracht. Uit die tabellen blijkt duidelijk de zeer goede gelijkenis tussen gegeven en berekende groei en aanwas voor hoogte en diameter van Populus euramericanu cv Marilandica.

Tot slot werd in tabel 8 een samenvattende vergelijking gemaakt tussen beide methodes, door zowel voor de diameter als voor de hoogte de gemiddelde 
afwijking te bepalen tussen berekende en gegeven aanwas $\left(\overline{\Delta y^{\prime}}\right)$ en hoogte $(\overline{\Delta y})$. Hierin zijn eveneens de overeenkomstige spreidingen $\mathrm{S} \overline{\Delta y^{\prime}}$ en $\mathrm{S} \overline{\Delta y}$ opgenomen.

Een t-test bij $\mathrm{P}=0.01$ heeft aangetoond dat er geen wezenlijk verschil bestaat tussen de nauwkeurigheid van de aanwasformules berekend volgens een van beide methodes. Voor de groeiformules is dit echter wél het geval, vermits men bij de grafische methode zowel voor de hoogte als voor de diameter cen gemiddelde fout vindt die praktisch nul is; terwijl voor de methode van Thomasius deze fouten respektievelijk $4,6 \mathrm{~m}$ en $7,9 \mathrm{~cm}$ bedragen.

\section{SUMMARY}

The adjustement of the growth-and increment formulas from BACKMAN in the case of missing data for the first years of growth

In the present paper, that starts with a critical evaluation of the method of Thomasius, the parameters from the growth-formula of Backman (a,b) are determined to work out the equalities (g), (h) and (i), by using the incrementformula (c). When the parameters $\mathrm{k}_{0}, \mathrm{k}_{1}$ and $\mathrm{k}_{2}$ are known, they are substituted in the equalities (d), (e) and (f), from which the parameters for the growthformula can be recovered.

This method was tested on data for height $\left(\mathrm{y}_{\mathrm{h}}\right)$ and diameter $\left(\mathrm{y}_{\mathrm{d}}\right)$ of Populus euramericana cv Marilandica (2nd quality) from the yield tables of Wiedemann-Schöber. (Tab. 1).

The results are summarized in table 3 . In tables 2 and 4 the comparison is made between the calculated results and the data for increment and growth from the yield tables of Wiedemann-Schober.

It thus appears that a very good similarity exists between the given data and the results obtained by use of the increment-formula. This is not the case for the growth formula on account of inadmissible systematic errors. These errors result from the indirect determination of the growth formula, that, infact, may not be used when data for the first years are unavailable.

To avoid these errors a "grafic method" is developped by the author. This method, clearly recaled to the method of Backman, requires less arithmetic-work to test the asymptotic values. In principle this method is based on the fact that in representing growth-progress in an axes-system (absis $\mathrm{t}$ for time and ordinate $y / J)$, all coordinated points $(t ; y / J)$ will be situated on a straightline, when the axes are graduated respectively in a logaritmic-and probabilityscale. This means, practically that the value of J has to be estimated till nearly all the points are on a straight-line. By adapting a line through these points, using the terms $(m)$ and $(p)$, it becomes possible to determine $c_{1}$ and $c_{2}$, while (q) gives the value for $c_{0}$. On the other hand, when the parameters of the growth-formula, are known the parameters of the increment-formula can be determinated by calculating (r), (s) and (v).

A comparison between data thus obtained and the data from table 1 is made in table 6. By a similar procedure as was used for the evaluation by the method of Thomasius, the author was able to clearly prove that a good similarity excists between given and calculated data on growth and increment for height and diameter of Populus euramericana cv Marilandica (Tab. 5 and 7).

In conclusion a comparison is made between both methods (Thomasius graphic method) (table 8 ) by determinating for diameter and height, the average deviation between the calculated and given values for increment $\left(\overline{\Delta y^{\prime}}\right)$ and growth $(\overline{\Delta y})$

A t-test for $\mathrm{P}=0,01$ proves that no essential difference excists between the precision of the increment formula, calculated according to either methods. This can not be said for the growth formula as the average errors, for height and diameter are nearing zero, while these errors are respectively $4,6 \mathrm{~m}$ and $7,9 \mathrm{~cm}$ for the method of Thomasius. 